\title{
LA PROFESIÓN DE TRABAJO SOCIAL ENTRE EL SIGLO XXI \\ ¿Qué podemos esperar? \\ ¿Qué está en nuestras manos hacer?
}

\section{Milagros Colón Castillo'}

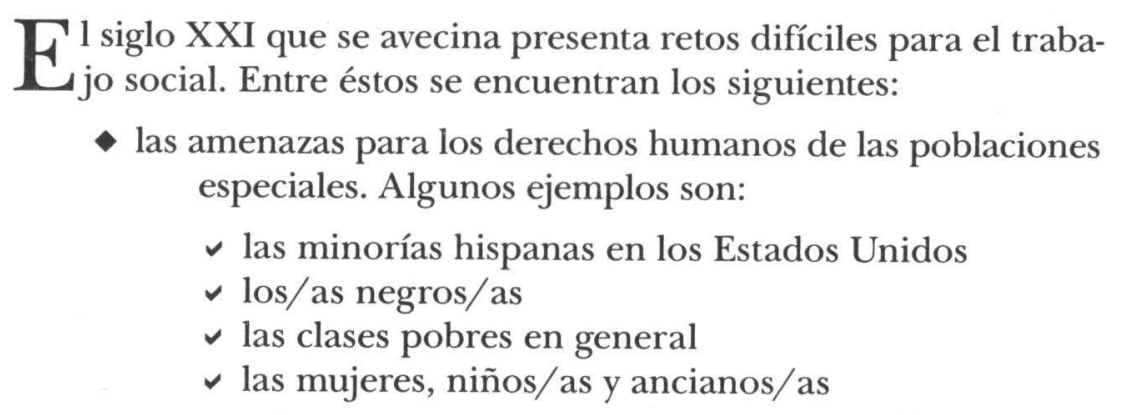

Estos retos se fundamentan en el hecho de que estas poblaciones no disfrutan de igual acceso a las oportunidades de desarrollar las destrezas que se requieren para competir en un mundo con mercados globalizados. Esto también afecta a la población de las personas con impedimentos.

Otro de los grandes retos es:

- el énfasis en la economía de los mercados mundiales - la globalización. El término globalización se define como la

\footnotetext{
${ }^{1}$ Catedrática Asociada, Universidad Interamericana de Puerto Rico, Recinto Metropolitano
} 
internacionalización e interdependencia de las economías nacionales en el marco de un planeta que tiende a ser una sola unidad económica y un gran mercado financiero (Borja, Enciclopedia de la Política citado en García Moure, 2000). Señala García Moure (2000) que la globalización actual es el resultado de ideas predominantes basadas en la concepción neoliberal y de decisiones políticas y económicas de actores claves e intereses geo-económicos y geo-políticos y en las grandes instituciones financieras internacionales. No es un fenómeno neutro sino que tiene un claro contenido ideológico y una concepción del ordenamiento del mundo.

Es precisamente este nuevo ordenamiento el que presenta un claro desafío a los/as profesionales que laboramos con las poblaciones de marginación y que son víctimas del proceso de exclusión social y política que impone la ideología de los mercados globalizados.

El fenómeno de la globalización parte del principio de que las destrezas mercadeables son aquellas que le permitirán a las personas competir en los mercados según las reglas establecidas por las multinacionales. Estas destrezas son, entre otras:

$\checkmark$ el dominio de la alta tecnología tanto en la industria como en el mundo de las comunicaciones

$\checkmark$ el dominio de más de un idioma

$\checkmark$ el dominio de las destrezas más elevadas de pensamiento crítico

$\checkmark$ el dominio total y absoluto de las destrezas de comunicación oral y escrita

A estos factores se suma el hecho de que los cambios económicos en el orden mundial han estimulado el desarrollo de economías subterráneas que afectan de forma directa a las poblaciones a las cuales somos llamados/as a servir. Señala Catalá (2000) la economía subterránea, particularmente su sector criminal encabezado por el tráfico de drogas, actúa como torcido factor de compensación ante el agotamiento de la economía formal.

Otras áreas de desafío, producto de la globalización pueden reconocerse en los siguientes elementos: 
- la promoción de las profesiones dirigidas al lucro en detrimento de las profesiones dedicadas al servicio

$\checkmark$ Las profesiones orientadas hacia el negocio, la producción, el apoyo a los procesos de industrialización y la empresa privada serán las que más impulso y promoción reciban de las grandes estructuras de poder. Entre éstas se pueden mencionar las comunicaciones, el mercadeo, la ingeniería, la programación y reparación de computadores.

$\checkmark$ Las profesiones de servicio que recibirán apoyo e impulso serán aquellas cuya orientación se dirija a fortalecer las tendencias del mercado global y cuya población esté en marcada en estas áreas de trabajo. La psicología industrial, la psicología clínica y la psiquiatría se encuentran entre estas profesiones de servicio privilegiadas por el mercado global.

Un reto de especial relevancia para los/las trabajadores sociales es:

- el aumento e intensificación de la pobreza en el nivel mundial Los países tercer mundistas quedarán rezagados en el desarrollo de los mercados globalizados. La población marginada por la pobreza quedará excluida en la medida en que exhibe características incompatibles con los requerimientos del mundo globalizado (Pérez Baltodano, 1997).

Ejemplos de estas características son:

$\checkmark$ falta de destrezas de comunicación oral y escrita

$\checkmark$ poco o ningún acceso a las fuentes de información, en especial las que provienen de la alta tecnología

- falta de dominio de otros idiomas, sobre todo del inglés

$\checkmark$ ausencia de educación formal

- la prevalencia de problemas enraizados en el discrimen por razón de género, edad, orientación sexual, raza y etnia. Se ha visto en los últimos tiempos el aumento de la intolerancia racial y étnica, los crímenes de odio, el resurgimiento del movimiento neo nazi, el fortalecimiento de la polarización de actitudes recalcitrantes en contra de grupos de diversidad humana y el aumento general en los niveles de violencia entre grupos, sectores, familias y parejas. 
¿Dónde queda la profesión de trabajo social ante estos retos? ¿Cuál es su situación y posición? ¿Qué podríamos esperar que ocurra en Puerto Rico en las primeras décadas del siglo XXI? Visualicemos dos posibles escenarios.

Escenario número 1 - la desaparición gradual pero consistente de la profesión de trabajo social.

Algunas manifestaciones que hacen posible la consideración de este escenario son las siguientes:

1. Se observa en varias agencias del servicio público una tendencia cada vez mayor a reducir las plazas de trabajo social sustituyéndolas por otras, con otros nombres y con funciones mucho más limitadas que las que la profesión abarca. El trabajo social como profesión parece estar en un peligroso proceso de tomarse en un quehacer invisible tal y como sucede con las poblaciones que están quedando excluidas por los procesos económicos en el nivel mundial.

2. En diversas agencias se están dando más y más el fenómeno de ver trabajadores/as sociales defendiendo sus funciones y las fronteras que delimitan y hacen única su profesión. Se puede observar una tendencia cada vez mayor a recibir el impacto de otras profesiones de servicio que reclaman que pueden realizar nuestras funciones con la misma o mayor efectividad.

3. En los escenarios de trabajo de los/as trabajadores/as sociales suele verse con mayor frecuencia el aumento de obstáculos y dificultades confrontadas cuando estos/as profesionales tienen que luchar por la reivindicación de los derechos de uno de los sectores poblacionales excluidos por la globalización.

Escenario número 2 - el fortalecimiento de la profesión de trabajo social y la reafirmación de su poder.

Los/as trabajadores/as sociales tenemos en el momento actual, la oportunidad y la necesidad de reconceptualizar el ejercicio de la profesión a la luz de lo que representa para nosotros y nosotras el reto del mundo global y de los fenómenos que ha traído la época post moderna. 
Para obtener el mayor beneficio de esta oportunidad que se nos presenta no podemos menos que empezar con el reconocimiento del hecho de que la mayor parte de la clientela a la cual servimos pertenece a esa gran población excluida, con muy pocas oportunidades de participar en los procesos mundiales que le afectan de forma directa y que limitan cada día más su oportunidad de lograr una vida de calidad. Por otra parte, tenemos que reflexionar sobre el hecho de que las tendencias que hemos descrito no parecen apuntar hacia el fortalecimiento de una profesión cuya misión se destina hacia la justicia social de las clases marginadas y oprimidas. Es ilusorio pensar que las grandes estructuras de poder político y económico en el mundo y en nuestros países van a dirigir su interés prioritario hacia las poblaciones que no les sirven a sus objetivos en cuanto a impulsar una economía de mercados mundiales se refiere. Entonces, nuestra reflexión nos tendría que conducir por necesidad a la conclusión de que el fortalecimiento y reafirmación de nuestro poder profesional tiene que surgir de nosotros y nosotras mismos/as.

Este cuadro presentado parece exigirnos que reclamemos nuestro espacio y rescatemos aquella misión que nos dio razón de ser como profesión. Ese esfuerzo hacia la reafirmación de nuestro poder como clase profesional nos permitirá dos posiblidades:

- prepararnos para el peor de los escenarios o

- construir el mejor de éstos

¿Qué instrumentos tenemos a fin de prepararnos para el peor de los escenarios?

- El fortalecimiento de la clase profesional en lo relativo a conocimientos:

$\checkmark$ dominio de los marcos teóricos y conceptuales

$\checkmark$ dominio en el acceso y uso de las fuentes de información

$\checkmark$ domino de las destrezas que exige la globalización (uso de la tecnología)

$\checkmark$ conocimientos y análisis de las tendencias en el nivel mundial y sus repercusiones en el ejercicio de nuestra profesión 
dominio de las destrezas de pensamiento crítico y analítico. Estas destrezas pueden ayudarnos a identificar las premisas subyacentes en los discursos de las estructuras dominantes. A su vez, esta identificación hará posible la interpretación de estas premisas a los sectores excluidos a quienes servimos a fin de aportar a su apoderamiento.

$\checkmark$ adquisición y desarrollo de destrezas relacionadas con el mundo de las finanzas para ponerlas al servicio de nuestra clientela. Entre éstas se encuentran la elaboración de presupuestos, la planificación estratégica, la elaboración o evaluación de propuestas, desarrollo de proyectos de autogestión.

mayor utilización de la revisión de la literatura para documentar nuestras gestiones profesionales.

En lo relativo a una actitud distinta:

$\checkmark$ uso de los mecanismos disponibles para el apoderamiento de la profesión y de la clientela - organismos profesionales y en especial el Colegio. La historia evidencia que los organismos profesionales de todas las disciplinas se han convertido en grupos de presión para impulsar determinadas políticas sociales y detener otras. El Colegio de Trabajadores Sociales de Puerto Rico es uno de los instrumentos de los cuales disponemos para hacernos sentir en la discusión de los asuntos de debate que nos afectan como profesionales o que afectan a nuestra clientela. Sin embargo, la utilización de este instrumento ha sido muy limitada y para muchos de nosotros/as el Colegio no ha pasado de ser el organismo que me obliga a pagar una cuota a cambio de asistir a una asamblea anual.

$\checkmark$ aumento en la actitud de defensa de la profesión ante sectores de la sociedad que no parecen conocerla (desde la legislatura hasta miembros de otras profesiones y el/la ciudadano/a común).

$\checkmark$ reconocer que nuestra autonomía profesional es posible y que debemos desarrollar más empresas para nuestra autogestión como profesionales. 
$\checkmark$ reconocer en nuestros colegas fuentes de apoyo para nuestros esfuerzos.

En lo relativo a la práctica de la profesión:

$\checkmark$ reconocer en la clientela la mayor fuente de apoyo y la justificación más convincente de la existencia de nuestra profesión. Es imperativo que nos digamos una y otra vez a nosotros/as mismos/as que somos imprescindibles para un sector poblacional que tienen en nosotros quizás la única oportunidad de lograr una vida con dignidad. Para muchas personas de la población excluida hemos sido y somos lo que ha hecho la diferencia entre tener acceso a un servicio o no tenerlo.

$\checkmark$ Promover el modelo de fortalezas y eliminar el uso del modelo de deficiencias que por años ha fomentado la dependencia emocional y física de las personas que les mantiene en la marginación y opresión.

¿Dónde radica la esperanza?

- En una clase profesional que por tradición ha mantenido su labor de denuncia en una búsqueda continua de la justicia. Ya hemos podido corroborar la tradición nuestra como una profesión que siempre ha estado donde tiene que estar.

- En los/as colegas de pasadas generaciones que continúan trabajando por las causas que la profesión defiende. De ellas y ellos tenemos aquí muy buenos modelos.

- En los/as colegas que se han dado a la tarea de abrir nuevos caminos para la práctica de la profesión a los fines de romper con aquellos esquemas que la encajonaban en la práctica asistencia. Señala la Dra. Seda Rodríguez (1997) hoy más que ayer, nuestro país demanda un trabajador social con una gran seguridad personal, sensible, creativo y comprometido con la justicia social y la solidaridad humana. Debe ser un estudioso y analista crítico de su realidad social y afirmativamente unirse al logro de metas orientadas al más pleno desarrollo de nuestro pueblo.

- En una generación nueva que no tiene miedo a romper viejos esquemas y sustituirlos por otros más efectivos; que 
busca renovarse conceptual y teóricamente de manera continua y que reclama su presencia en las luchas por los derechos humanos.

Recojo en mi reflexión final las palabras de la Dra. Seda Rodríguez cuando afirma que los trabajadores sociales debemos y podemos ser actores en una obra de transformación social. Seamos militantes comprometidos en la lucha para erradicar la dependencia existencial en que se encuentra atrapado nuestro pueblo. He ahi el mayor desafí a que se enfrenta nuestra profesión. Hemos pues de convertirnos en esa profesión que nuestra clientela espera que seamos. Tenemos que ser esa clase profesional que no sólo se resiste a desaparecer sino que insiste en reafirmar su poder. Eso somos y eso tenemos que ser para el bien de nuestra clase y de nuestra clientela: Una profesión reafirmada en el poder de cambio de las condiciones de opresión e injusticia a una realidad de mayor respeto y dignidad.

\section{Referencias}

Banks S. (1997). Etica y Valores en el Trabajo Social. Primera edición. Barcelona: Ediciones Paidós.

Bianchi, E. (1994). El Servicio Social como Proceso de Ayuda. Primera Edición. Barcelona: Ediciones Piados.

Catalá Oliveras, F.A. (2000). Economía, Desarrollo y Trabajo publicado en Memorias de la Cumbre Social celebrada en Dorado, Puerto Rico el 2 y 3 de marzo de 2000.

García Moure, E. (2000). Mundialización, Globalización y Marginalidad Social. Publicado en Memorias de la Cumbre Social celebrada en Dorado, Puerto Rico el 2 y 3 de marzo de 2000.

Hancock, M.R. (1997). Principles of Social Work Practice. Binghampton, NY: The Haworth Press.

Pérez Baltodano, A. (1997). Globalización, Ciudadanía y Política So- 
cial en América Latina: Tensiones y Contradicciones. Venezuela: Editorial Nueva Sociedad.

Reamer, F.G. (1990). Ethical Dilemmas in Social Service. Segunda Edición. New York: Columbia University Press.

Rivera de Ríos, T. (1986). Carmen Rivera de Alvarado: Lucha y Visión de Puerto Rico Libre. Fundación Carmen Rivera de Alvarado y Antonio Alvarado.

Saleebey, D. (1997). The Strengths Perspective in Social Work Practice. Segunda Edición. New York: Longman Publishers.

Seda Rodríguez, R. (1997). Evolución y Proyecciones de la Práctica del Trabajo Social: Tendencias y Desafíos. Ponencia presentada en la Conferencia Conmemorativa Dorothy D. Bourne el viernes 14 de marzo de 1997. 
